\title{
An Innovative Way by Manipulating Things using the Power of Thought
}

\author{
Kalaiselvi B, Vijayan T, Sridharraja D, Abinethri R
}

\begin{abstract}
Using the force of thought to control the earth might appear like a thing removed from sci-fi books. Be that as it may, the advancements we see today were once sci-fi beginning from man arriving on the moon to examine in teleportation. Thus controlling the surroundings through musings is likewise one of the apexes of that development called Brain Computer Interface. Utilizing cerebrum waves measured of an EEG to control PC. The contemporary remote control is supplanted by the force of one's idea which couldturn considerations into reality. The application ranges from utilizing contemplations to play diversions to re-wiring of the brain.The numerous unending potential outcomes extrapolated from this innovation could be of Controlling prosthetic appendages, robots, $P C$ and practicing the cerebrum to rewire itself in stroke patients. The thought of this is basic, utilizing the typical EEG estimation that distinguishes the electrical yield of the cerebrum and utilizing them as a data to different gadgets As no persons contemplations are same; this framework gives distinction to the one utilizing it. Deadened patients who can't utilize their appendages and persons experiencing 'secured disorder' whose cerebrum action are all the same can connect utilizing this kind of non intrusive BCI. This paper is a tricky study that considers in the domain of this advancement distinguishing both its advantages and disadvantages as it prompts another time of savvy advances for what's to come. [1],[3],[5]
\end{abstract}

Keywords : Brain Computer Interface $(\mathrm{BCI})$;

Electroencephalogram(EEG);General Terms-Paralysis;Locked in syndrome;

\section{INTRODUCTION}

The way human beings engage with computer systems has reformedconsiderablyin the past many years. within the starting human to gadget interfaced turned into performed the usage of keyboards, then later thru hand movements using a computer mouse, other capability enter sources had been spread out allowing more in-constructed and clean manipulate, as an example, based on speech, gestures or eye moves all relying on a functional motor device. [2 ],[ 4],[6] $\mathrm{BCI}$ is a manner of taking the interaction to the following stage. It uses the notion waves which are normally produced at some stage in an movement capacity and makes use of it as a supply of enter to interface with machines. the leading edge of this revolutionary idea is a transportable non-invasive EEG

Revised Manuscript Received on August 22, 2019.

B.Kalaiselvi, Department of EIE, Bharath Institute of Higher education and research, Tamilnadu, India. Email: kalaiselvi.eie@bharathuniv.ac.in

Sridhar Raja D Department of EIE, Bharath Institute of Higher Education and Research, Tamilnadu, India. Email: sridharraja.eie@bharathuniv.ac.in

T.Vijayan, Department of EIE,Bharath Institute of Higher education and research, Tamilnadu, India. Email: vijayan.eie@bharathuniv.ac.in

R.Abinethri, Department of EIE, Bharath Institute of Higher education and research, Tamilnadu, India. Email: abi.eie@ bharathuniv.ac.in headset from Emotiv EPOC system that could flip mind into fact. [7],[9], [11]

\section{BACKGROUND}

EEG waves are made by using the terminating of neurons inside the cerebrum and have been to start with measured with the aid of Vladimir Pravdich-Neminsky who measured the electric motion inside the brains of mutts in 1912,although the term he utilized waselectrocerebrogramTen years after the reality Hans Berger became the first to gauge EEG waves in people and, notwithstanding giving them their advanced call, started the examination of the use of these electric approximations in the base of neuroscience and mind studies. EEG waves are measured utilizing anodes joined to the scalp that are touchy to modifications in postsynaptic opportunities of neurons in the cerebral cortex. Postsynaptic possibilities are made by the combination of inhibitory and excitatory opportunities located inside the dendrites. those opportunities are made in degrees of close by depolarization or polarization taking after the adjustment in film conductance as neurotransmitters is discharged. one of the chronicled drawbacks of EEG estimation has been the debasement of EEG statistics by using antiques which might be electric signs which might be gotten by means of the sensors that do not start from cortical neurons. A standout among the maximum extensively identified reason for curios is eye improvement and flickering, however one of a kind reasons can contain the improvement distinctive muscle mass or maybe terrible contact among the scalp and the electrodes.Many EEG frameworks enterprise to diminish antiquities and preferred commotion through the usage of reference anodes installed areas where there's minimal cortical motion and endeavoring to sift thru related patterns. [8],[ 10] ,[12]

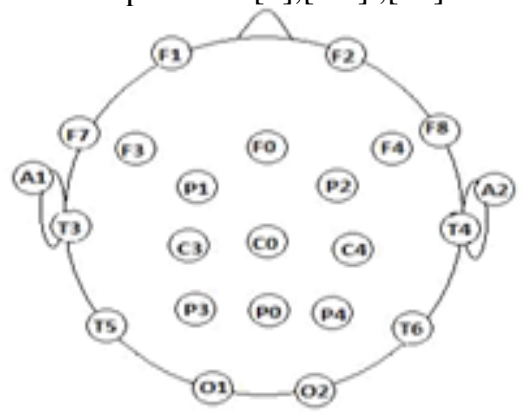

Figure2. Electrode

In figure 1 the Electrode Placement in line with the international 10-20 gadget is proven. peculiar numbers at the proper,even numbers on 
the left. Letters correspond to lobes - (Frontal), (Temporal), (Parietal), and (Occipital). C stands for vital (there's no primary lobe).For achieving the EEG, the special tactics carried are 6 electrodes, 21 electrodes with $10-20$ lead structures, 27 electrodes overlie the sensory motor areas, sixty four scalp electrodes overlie on scalp or even more wide varietyof electrode in array fashion. type of the capabilities is accomplished by using using certainly one of Bayer's classifier, Adaptive good judgment community,

threshold detection, again Propagation neural network. maximum applicable component in EEG-signals are extracted via FFT analysis, autoregressive (AR) models, spatial pattern technique, Hilbert transform and so on from complete frequency band or any of alpha, breeta or mu bands. [14], [ 16], [18]

\section{METHODOLOGY}

The main idea of this paper is to manipulate things in real time using the measured EEG Signal.

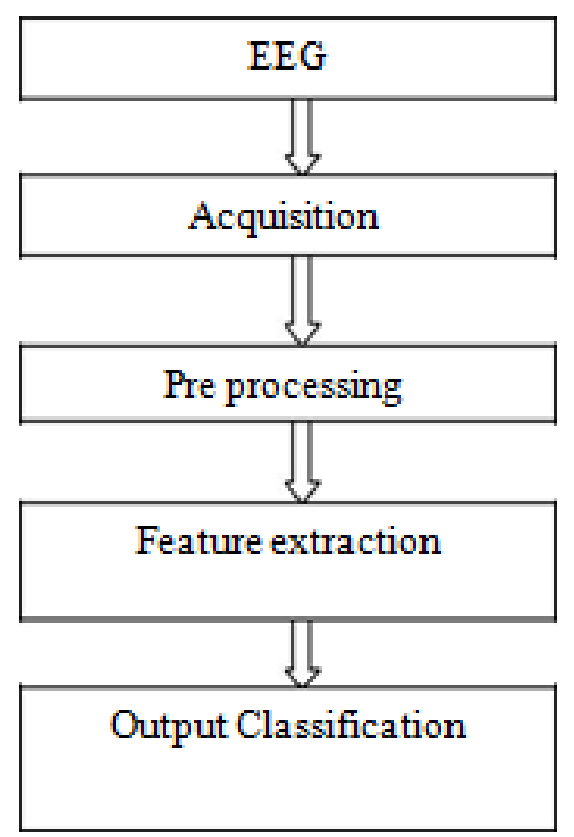

Figure 2. Block diagram for Brain-Computer Interface

The EEG sign extraction and otherenvironment manipulations is accomplished inside the procedure particular as brain-pc Interface method. Themeasured EEG waves are Preprocessed and the specified signal on my own is extracted leaving out Artifacts and other additives in the spectrum. With the extracted signal the specified challenge is been achieved thereby manipulating the matters in real international.The concept is nicely made using The Emotiv(C) SystemwhichisEPOCheadset.The EPOC has 14 electrodes(compared to the 19 electrodes of a wellknown clinical EEG, and the three of OCZ's NIA geologies and a few of Neuro Sky's unmarried anode). It likewise has a -hub gyro for recognizing head trends. [13], [15] ,[ 17]

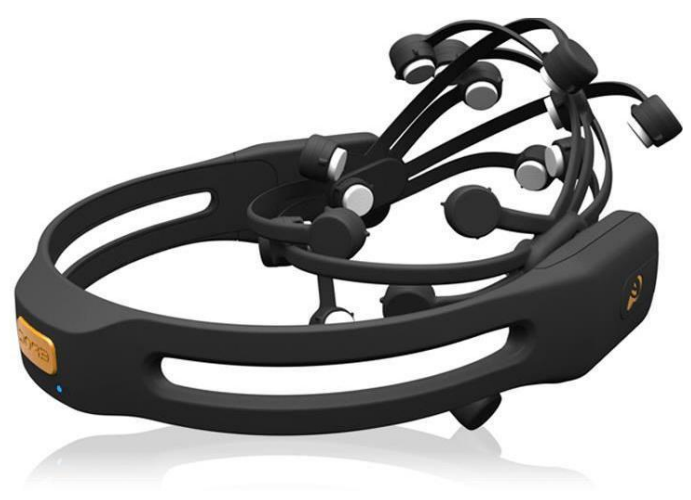

Figure 3.Emotiv Epoc Headset.

conscious mind (Cognitiv suite): The devicedetects thirteen varieties of movement - six guidelines (left, proper, up, down, forward, and "pull/zoom") and six rotations (anti-clockwise rotation, flip left and right, and sway to and fro), plus one other visualization ("disappear"). whilst the contemporary motive force may additionally only be capable of pay attention for any four of these at a time, the degrees of freedom are larger than a joystick's $2 \mathrm{df}$. Ideomotorreactions or the much extra grounded EMG streams apart, these thought due to the fact about the mind boggling location calculations blanketed, there may be a moderate slack in figuring out musings. then again, the innovation may anyhow be helpful in a bolster part like ringing a minimap or radar in a FPS diversion.

- emotions (Affectiv suite): "exhilaration","Engagement/Boredom", "Meditation", and "Frustration" can right now be measured. Emotiv concedes that the names might not impeccably replicate exactly what the feeling is, and says that they is probably renamed before enterprise quarter dispatch.

Facial expressions (Expressiv suite): Singular eyelid and eyebrow positions, eye position in the level aircraft, grinning, snickering, retaining, and smiling can at gift be recognized. different expressions is probably introduced preceding discharge. The expressions are identified via the EEG sensors getting signs and symptoms to facial muscular tissues, instead of by using perusing brainwaves. multiple to perusing intellectual action, these region are brief (10ms)conveying a definitive favorable function and rendering them appropriate for quick paced recreations within the FPS type.

- Head rotation: the suitable velocity of one's head may be measured within the yaw and pitch (however no longer pass) headings. that is outstanding by way of gyros, and isn't diagnosed with the EEG highlights. 


\section{RESULTS AND DISCUSSION}

The measured EEG signal using Emotiv is been shown in Figure 4.

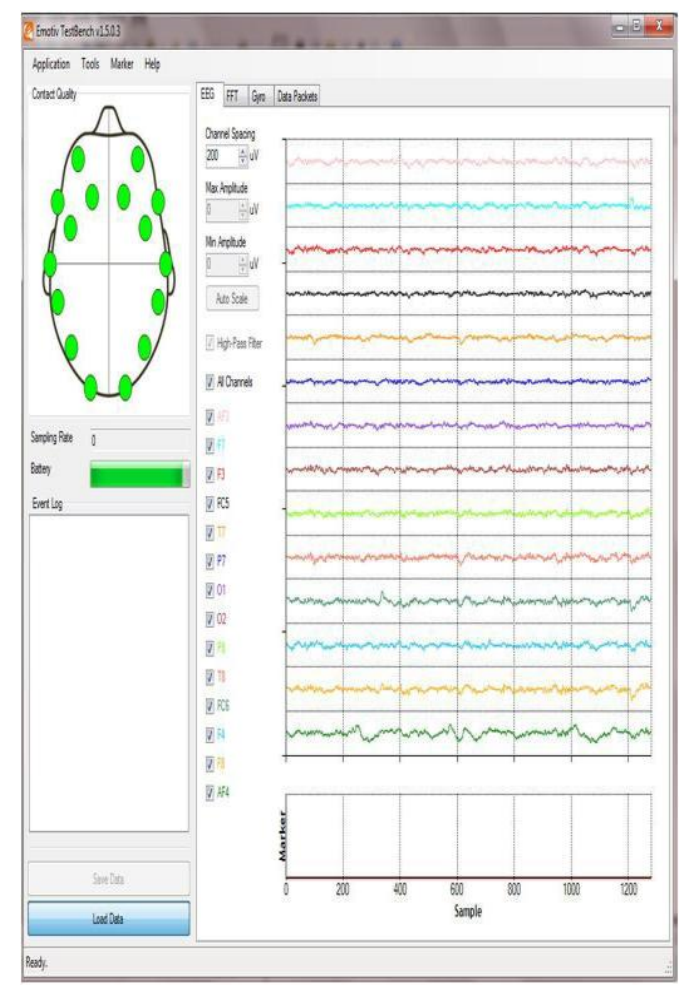

Figure 4.Measured EEG wave

\section{CONCLUSION}

The term Brain-Computer Interface initially showed up in exploratory writing in the 1970's, however the thought of connecting the psyche to PCs was nothing new.The extreme objective of BCI research is to make a framework that not just an open loopsystem that reacts to clients considerations however a closed loopsystem that additionally offers criticism to the client. Specialists at first centered around the engine cortex of the cerebrum, the range which controls muscle developments, and testing on creatures immediately demonstrated that the normal learning practices of the mind could without much of a stretch adjust to new boosts and additionally control the terminating ofspecific zones of the brain. This research managed basically with intrusive methods however gradually calculations rose which could interpret the engine neuronresponses in monkeys progressively and make an interpretation of them into automated activity.Recently, a framework created by analysts and CarnegieMellon University and the University of Pittsburgh permitted a monkey to encourage itself through a prosthetic arm utilizing just its musings. This examination is amazingly encouraging for the debilitated, and in reality by 2006 a framework was created for a tetraplegiac that empowered him to utilize prosthetic gadgets, a mouse cursor, and a TV through a 96-smaller scale cathode exhibit embedded into his essential engine cortex.Thereby demonstrating it as a continuous variable control utilizing musings. The potential outcomes accomplished through this could be perpetual and clears a route for another time of cooperation with machines. [19],[20],[21]

\section{REFERENCES}

1. Sharma, R.K., Irusapparajan, G. \& Periyaazhagar, D. 2019 , "Three-phase symmetric cascading Z-source seven levels multilevel inverter excited by multi carrier sinusoidal pulse width modulation scheme", International Journal of Innovative Technology and Exploring Engineering, vol. 8, no. 10, pp. 4269-4274

2. Velavan, R., Bharanidharan, S. \& Sheeba, B. 2019, "EMF pollution Causes, effects and protection", International Journal of Innovative Technology and Exploring Engineering, vol. 8, no. 9 Special Issue 3, pp. 1166-1168.

3. Saravana, S., Balaji, S., Arulselvi, S. \& John Paul Praveen, A. 2019, "Reliable power quality monitoring and protection system", International Journal of Innovative Technology and Exploring Engineering, vol. 8, no. 9 Special Issue 3, pp. 644-645.

4. Tamil Selvan, S. \& Sundararajan, M. 2019, "Performance Parameters of 3 Value 8t Cntfet Based Sram Cell Design Using H-Spice", International Journal of Recent Technology and Engineering, vol. 8, no. 2 Special issue 5, pp. 22-27.

5. Jac Fredo, A.R., Abilash, R.S., Femi, R., Mythili, A. \& Kumar, C.S. 2019, "Classification of damages in composite images using Zernike moments and support vector machines", Composites Part B Engineering, vol. 168, pp. 77-86.

6. Kathiravan, P. \& Govindaraju, C. 2019, "Design and evaluation of ultra gain isolated DC-DC converter for photovoltaic system", International Journal of Engineering and Advanced Technology, vol. 8, no. 5, pp. 2646-2651.

7. Kripa, N., Vasuki, R. \& Kishore Kanna, R. 2019, "Realtime neural interface controlled au-pair BIMA bot", International Journal of Recent Technology and Engineering, vol. 8, no. 1, pp. 992-994.

8. Mohanraj, Meenaa Kumari, M., Philomina, S. \& Jasmin, M. 2019, "In-situ humidity measurement of hydrogen fuel cell car using MEMS sensor", International Journal of Recent Technology and Engineering, vol. 8, no. 1, pp. 41-43.

9. Velmurugan, T. \& Prakash, S. 2019, "Artificial intelligent based distribution automation of swift fault detection isolation and power restoration for HT network", International Journal of Innovative Technology and Exploring Engineering, vol. 8, no. 6, pp. 1-6.

10. Dwarakesh, K. \& Prem Kumar, G. 2019, "Five-level inverter based sequential boost system using fuzzy logic controller", International Journal of Innovative Technology and Exploring Engineering, vol. 8, no. 6 , pp. $12-19$.

11. Anne Gifta, A. \& Hemavathi, G. 2019, "Analysis of grid tied solar PV system using ANFIS Algorithm", International Journal of Innovative Technology and Exploring Engineering, vol. 8, no. 6, pp. 312-316.

12. Jayavel, R., Rangaswamy, T.R. \& Prakash, S. 2019, "Efficient grid management system with renewable and conventional power sources", International Journal of Innovative Technology and Exploring Engineering, vol. 8, no. 6, pp. 287-289.

13. Hemavathi, G. \& Maheshwaran, S. 2019, "Proportional resonant controlled high gain step-up converter system with improved response", International Journal of Innovative Technology and Exploring Engineering, vol. 8, no. 6, pp. 317-323.

14. Periyaazhagar, D. \& Irusapparajan, G. 2019, "Design and completion of asymmetric single phase 27 level cascaded mli for various pwm scheme", International Journal of Innovative Technology and Exploring Engineering, vol. 8, no. 6, pp. 792-797.

15. Mahalakshmi, V. \& Vijayaragavan, S.P. 2019, "PV based power electronic converters for high voltage DC applications", International Journal of Recent Technology and Engineering, vol. 7, no. 6, pp. 670-674.

16. Irusapparajan, G., Periyaazhagar, D., Prabaharan, N. \& Rini Ann Jerin, A. 2019, "Experimental verification of trinary DC source cascaded h-bridge multilevel inverter using unipolar pulse width modulation", Automatika, vol. 60, no. 1, pp. 19-27.

17. Sangeetha, G., Sherine, S., Arputharaju, K. \& Prakash, S. 2019, "On Line Monitoring of Higher Rated Alternator using Automated Generator Capability Curve Administer", Proceedings of the IEEE International Conference on \&amp;quot;Recent Trends in Electrical, Control and

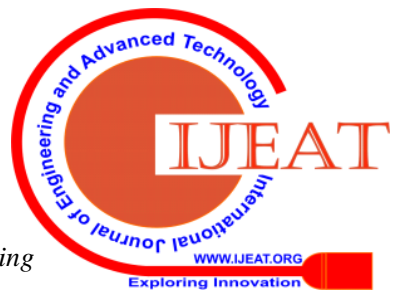


Communication\&amp;quot;, RTECC 2018, pp. 176.

18. Bycil, V.J. \& Wiselin, M.C.J. 2019, "Modeling and analysis of vibration energy harvesting system using piezo stack", International Journal of Mechanical and Production Engineering Research and Development, vol. 9, no. Special Issue 1, pp. 523-533.

19. Sripada, A., Warrier, A., Kapoor, A., Gaur, H. \& Hemalatha, B. 2018, "Dynamic lateral balance of humanoid robots on unstable surfaces", International Conference on Electrical, Electronics, Communication Computer Technologies and Optimization Techniques, ICEECCOT 2017, pp. 539.

20. Srinivasan, S., Thirumalaivasan, K. \& Sivakumaran, T.S. 2018, "Performance evaluation of double-output luo converters", Journal of Advanced Research in Dynamical and Control Systems, vol. 10, no. 10 Special Issue, pp. 870-878.

21. Karthikayen, A. \& Selvakumar Raja, S. 2018, "A skellam distribution inspired trust factor-based selfish node detection technique in MANETs", Journal of Advanced Research in Dynamical and Control Systems, vol. 10, no. 13, pp. 940-949.

\section{AUTHORS PROFILE}

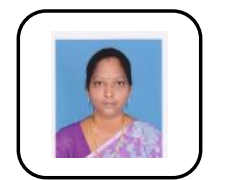

B.Kalaiselvi, Assistant Professor, Department of EIE,Bharath Institute of Higher education and research, Tamilnadu, India

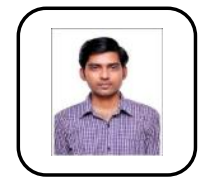

T.Vijayan, Assistant Professor, Department of EIE,Bharath Institute of Higher education and research, Tamilnadu, India.

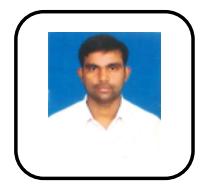

Sridhar raja D, Assistant Professor, Department of EIE,Bharath Institute of Higher education and research, Tamilnadu, India.

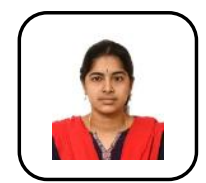

R.Abinethri, Assistant Professor, Department of EIE,Bharath Institute of Higher education and research, Tamilnadu, India 